\title{
Usual coffee intake in Brazil: results from the National Dietary Survey 2008-9
}

\author{
Alessandra Gaspar Sousa ${ }^{1 *}$ and Teresa Helena Macedo da Costa $^{2}$ \\ ${ }^{1}$ Human Nutrition Graduate Course, School of Health Science, University of Brasilia, Brasilia, Brazil \\ ${ }^{2}$ Department of Nutrition, School of Health Science, University of Brasilia, Darcy Ribeiro Campus, \\ 70919-970 Brasilia, Brazil
}

(Submitted 19 November 2014 - Final revision received 4 February 2015 - Accepted 20 February 2015 - First published online 8 April 2015)

\section{Abstract}

Coffee is central to the economy of many developing countries, as well as to the world economy. However, despite the widespread consumption of coffee, there are very few available data showing the usual intake of this beverage. Surveying usual coffee intake is a way of monitoring one aspect of a population's usual dietary intake. Thus, the present study aimed to characterise the usual daily coffee intake in the Brazilian population. We used data from the National Dietary Survey collected in 2008-9 from a probabilistic sample of 34003 Brazilians aged 10 years and older. The National Cancer Institute method was applied to obtain the usual intake based on two nonconsecutive food diaries, and descriptive statistical analyses were performed by age and sex for Brazil and its regions. The estimated average usual daily coffee intake of the Brazilian population was 163 (SE 2.8) ml. The comparison by sex showed that males had a $12 \%$ greater usual coffee intake than females. In addition, the highest intake was recorded among older males. Among the five regions surveyed, the North-East had the highest usual coffee intake $(175 \mathrm{ml})$. The most common method of brewing coffee was filtered/instant coffee ( $71 \%$ ), and the main method of sweetening beverages was with sugar (87\%). In Brazil, the mean usual coffee intake corresponds to $163 \mathrm{ml}$, or $1.5 \mathrm{cups} / \mathrm{d}$. Differences in usual coffee intake according to sex and age differed among the five Brazilian regions.

\section{Key words: Coffee: Usual intake: Brazilian population: Diet surveys: Beverages}

Coffee is essential to the economy and politics of many developing countries, and its importance in the world economy is unquestionable. This beverage is an important generator of wealth in the world, and Brazil is the world's largest producer and exporter of coffee ${ }^{(1)}$. Brazil is also the second largest consumer market for coffee, and coffee is the second most consumed food in Brazil, with a prevalence of $79 \%$ (estimated with data from only $1 \mathrm{~d}$ of food intake) ${ }^{(2)}$.

Individual cultures are influenced by ancient traditions and modern habits as well as by differences in preparation, types of coffee and additional ingredients, but each finds the motivation and a unique way to appreciate coffee. The consumption of coffee as a beverage throughout the world has a history dating back thousands of years, but only in the past few decades has evidence been found to support the notions that coffee is a complex chemical mixture and can be considered a functional and nutritional food ${ }^{(3-5)}$.

Despite the widespread use of and interest in coffee, there are very few data available about its usual intake ${ }^{(6,7)}$. Usual intake is defined as long-term average intake, which is required information for most epidemiological diet analyses.
According to the National Cancer Institute (NCI), there are two approaches to estimate usual intake distributions: one approach measures nutrients and food groups that are consumed on a daily basis, and the second measures foods or nutrients that are consumed episodically (e.g. vitamin A or vitamin $\mathrm{B}_{12}$ ). For beverages like coffee, the episodically consumed model should be used. Therefore, the model for measuring the usual intake of coffee fits a two-part mixed model that contains both the probability of consumption and the amount consumed ${ }^{(8)}$.

To our knowledge, no previous studies have examined usual coffee intake using the most recently available dietary data from the 2008-9 Brazilian National Dietary Survey ${ }^{(9)}$. Data on individual food intake, when correctly obtained and analysed, are important for guiding health and nutrition policies as well as helping establish relationships between habitual dietary intake and health outcomes. Thus, it is necessary to assess food intake at both the individual and population levels ${ }^{(10)}$. The aim of the present article was to characterise the usual daily intake of coffee in the Brazilian population. Additionally, we investigated the different forms of coffee

Abbreviations: HBS, Household Budget Survey; NCI, National Cancer Institute; PSU, primary sample units.

*Corresponding author: A. G. Sousa, email alessandragaspars@gmail.com 
intake and considered the methods of coffee preparation in the studied population.

\section{Materials and methods}

\section{Sample design}

The present study was based on the 2008-9 Household Budget Survey (HBS) consumption module, also known as the National Dietary Survey, which was conducted by the Brazilian Office of Statistics and Geography (IBGE - Instituto Brasileiro de Geografia e Estatística). The 2008-9 HBS is a national database of household goods and food availability as well as family consumption which enables the analysis of trends and international comparisons. A module of individual food intake was introduced into the 2008-9 HBS which provided estimates of food and nutrient consumption. If repeated in the future, the National Dietary Survey will help identify patterns of temporal changes in food consumption in $\mathrm{Brazil}^{(9)}$.

The 2008-9 HBS had a complex sample design and was carried out as a two-stage sampling process. In the first stage, the primary sample units (PSU) were selected based on the 2000 census, and they were stratified geographically and by the socio-economic characteristics of the stratum. In the second stage, the sampled units included households that were selected by simple random sampling. The total number of households that provided information about individual food consumption was 13569 (which corresponds to $24.5 \%$ of the households that participated in the 2008-9 HBS). The selection procedure for the subsample guaranteed the presence of households from all PSU and is thus representative of the national population. The information on individual food consumption was obtained from 34003 individuals, who provided two nonconsecutive days of food records ${ }^{(9)}$.

\section{Coffee intake and sugar addition to beverages}

Coffee intake was estimated by considering the methods of coffee preparation (e.g. filtered coffee, espresso, cappuccino, etc.) contained in the National Dietary Survey, including coffee preparation at home and coffee consumption in coffee shops and diners. 'Coffee with flour' (a preparation method used in some regions of Brazil which involves adding cassava flour to coffee) was not included among the forms of preparation, because it has a very low prevalence (0.03\%). We calculated that preparation methods such as soluble cappuccino (in traditional, light and diet forms) and coffee from a machine represented one-third of the total volume consumed. On the other hand, 'espresso', 'morning coffee' and 'coffee filtered/instant' represented the total amount of coffee consumed. Finally, the 'filtered/instant coffee with milk' preparation method was calculated to be $50 \%$ coffee and $50 \%$ milk of the total volume consumed. Decaffeinated coffee was not included in the National Dietary Survey, and thus we were not able to include it in the present research.

The information regarding the addition of sugar to beverages in the National Dietary Survey was estimated by asking respondents during the home interview to identify the type of sweetener they usually added to beverages, including sugar, no-energy artificial sweeteners, both or none ${ }^{(11)}$.

\section{Statistical analysis}

As mentioned earlier, we used the NCI method ${ }^{(12)}$ to characterise the usual intake of coffee in the Brazilian population. The NCI method estimates the usual intake distributions for episodically consumed dietary components, such as foods which exhibit a large proportion of zero intake on any given day. The centrepiece of the NCI method is a two-part model for repeated measures analyses with correlated random effects, and it requires two or more $24 \mathrm{~h}$ recalls on at least one random subset of the population. The model separates usual intake into two parts: the probability of consuming a food on a particular day and, if the food was consumed, the amount eaten on the day of consumption. The first part estimates the probability of consumption using logistic regression with a person-specific random effect, whereas the second part specifies the consumption-day amount using linear regression on a transformed scale, also with a person-specific effect. The first and second parts are linked by allowing the two personspecific effects to be correlated and by including common covariates in both parts of the model ${ }^{(8,13)}$.

We applied macros developed by the NCI in the Statistical Analysis System (SAS) software programme. For a single dietary component, two macros are available: the first macro, MIXTRAN, transforms the data and fits the model. The second macro, DISTRIB, uses the parameters that are estimated by MIXTRAN to estimate the usual intake statistics through simulation ${ }^{(13)}$.

The NCI method can also be used in complex surveys. However, to analyse data from a complex survey, the standard error calculation requires additional programming to implement a replication method, such as Fay's Balanced Repeated Replication method ${ }^{(13)}$.

Fay's Balanced Repeated Replication method was developed for specific situations in which there are two PSU per stratum design, and the Brazilian Dietary Survey has more than two PSU per stratum. To overcome this restriction, the usual method is to randomly group the PSU in each stratum into two groups and then apply the Balanced Repeated Replication procedure. This is the so-called grouped balanced half-sample method. Details of all of these procedures were published by Barbosa et al. ${ }^{(13)}$ and were followed here to obtain usual coffee intake.

The analysis of the frequencies and the macros for usual intake were performed in SAS version 9.3 (SAS Institute, Inc.). Descriptive statistics, such as means, standard errors and percentiles, were used to present the characteristics of coffee intake by sex and age categories.

\section{Results}

The estimated average usual daily coffee intake from the total population was $163(\mathrm{SE} 2 \cdot 8) \mathrm{ml}$, and the median was $129 \mathrm{ml}$. The 5th and 95th percentiles were 3 (SE 0.5) and 442 (SE 7.9), respectively (Table 1 ). In the male and female subgroups, 
there was modest variation with age but no difference among the age groups, which was shown by the overlapping CI. Notably, adult and older males drank more coffee as compared to adult and older females, respectively. Moreover, older males (aged $>60$ years) for the 25th and 95th percentiles had a higher daily usual coffee intake than older females. Adult (aged 19-59 years) and older males for the 50th, 75th and 90th percentiles had a higher daily coffee intake than females (Table 1). Therefore, in Brazil, the distribution of daily usual coffee intake is 8 to $12 \%$ higher for adult (aged 19-59 years) males than it is for females and 19 to $25 \%$ higher in older (aged $>60$ years) males than females (Table 1).

The estimated mean of usual coffee intake from the North, Midwest, South, South-East and North-East regions was 135 (SE 2.3), 144 (SE 2.3), 153 (SE 6.3), 166 (SE 3.4) and 175 (SE 9.4) $\mathrm{ml}$, respectively. Thus, the highest daily usual coffee intake was obtained for the North-East Region, and the 5th and 95th percentiles for this region were 3 and $470 \mathrm{ml}$ of coffee/d, respectively (online Supplementary material).

The usual daily coffee intake varied between adult men and adult women in the North and Midwest regions and between older men and older women in the South-East and North-East regions. The South Region presented no sex and age differences in coffee intake. Female teenagers from the North Region had a higher coffee intake as compared to adults but not to older women. In males, there were no mean age differences in any of the regions, but North-Eastern men and women drank more coffee than Northern and South-Eastern men and women in all of the age subgroups. The highest daily usual intake (95th percentile) was observed for older (aged $>60$ years) North-Eastern men, with a value of 521 (SE 13.6) $\mathrm{ml}$ of coffee (online Supplementary material).

The coffee brewing and preparation method most commonly used by Brazilians was filtered/instant coffee (71\%), followed by coffee with milk (53\%). The consumption of cappuccino and espresso coffee was low in the studied population: 0.5 and $0.1 \%$, respectively.

Sugar was the main method of sweetening beverages (87\%), followed by sweetener (7\%) and the combination of both during the day (5\%). Only $1 \%$ of participants did not use any type of sweetener in their beverages.

\section{Discussion}

The method described in the present article estimates the distribution of usual daily coffee intake among Brazilians. In the present study, the mean usual daily coffee intake was 163 ( $\mathrm{SE} 2 \cdot 8) \mathrm{ml}$, and if we assume a cup size to be $120 \mathrm{ml}$ (which is most common in Brazil), this means that coffee intake was approximately $1.5 \mathrm{cups} / \mathrm{d}$. Clearly, there are larger differences between countries than the size of cups, and these discrepancies make comparisons difficult. Machado et $a l .{ }^{(14)}$ listed the cup volumes reported by cross-sectional studies on coffee intake and type 2 diabetes and found that they varied, with volumes of $240 \mathrm{ml}$ in Finland and $150-200 \mathrm{ml}$ in Sweden, Greece and Japan. In Brazil and the Netherlands, cups contained $120-125 \mathrm{ml}$. 
Taking into account the differences in cup sizes, the present findings differ from other studies conducted in Greece, the Netherlands, France, Sweden, Germany and Spain ${ }^{(15-19)}$. In these European studies, the mean coffee intake was about 2-4 cups/d (i.e. 4-8 Brazilian cups/d).

Information on usual daily coffee intake is scarce. Most studies report that after water, coffee is the beverage with the largest proportion of adults reporting consumption. In Canada, among coffee consumers, consumption peaked at age 31 to 50 years and averaged $639 \mathrm{~g}$ for men and $586 \mathrm{~g}$ for women. By age 71 years and older, the average amounts were considerably lower, at 489 and 398 g, respectively ${ }^{(7)}$. Another study that used data from the National Health and Nutrition Examination Survey (NHANES) showed similar results, with the usual coffee intake decreasing after age 71 years and averaging $406 \mathrm{ml}$ as compared to $515 \mathrm{ml}$ among adults aged 51-70 years ${ }^{(6)}$. The present results are in agreement with those studies that showed an age change in coffee intake, although there are differences in age stratification.

The present study showed that older males had a higher volume of usual coffee intake than older females, and no difference was identified within the age groups between males and females. In contrast, Demura et al. ${ }^{(20)}$ found that younger males drank more coffee than younger females in Japan. Nonetheless, other studies conducted in Brazil ${ }^{(21)}$ and France $^{(22)}$ reported that the average coffee consumption among female participants was higher than that in male participants.

The present results showed no difference in mean coffee intake within age groups for females and males in Brazil. This is inconsistent with previous studies that reported higher coffee consumption among younger individuals ${ }^{(16,23)}$ and among older individuals ${ }^{(5,21)}$. It also contrasts with results from the Brazilian Association of Coffee Industries (ABIC - Associação Brasileira da Indústria do Café) that showed an age reduction in the consumer public ${ }^{(1)}$.

As seen in these earlier studies, the amount of coffee consumption varies greatly across different regions of the world. Even within the same population, individuals have very different consumption patterns ${ }^{(4)}$. In the present study, the highest intake of coffee was in the North-East Region, followed by the South-East Region. These results are in agreement with the study of Souza et $a l{ }^{(2)}$, which found that coffee was the most prevalently consumed item in the North-East Region based on data from the first day of the food record. Similarly, Andrade et al. ${ }^{(24)}$ found that coffee was among the most frequently consumed food items in the city of Rio de Janeiro, which is in the South-East Region.

The present study also found that the most common method for brewing coffee was infusion (cloth strainer and filter paper). This method is also called drip coffee, because the preparation involves pouring hot water over roasted, ground coffee beans contained in a filter. Conversely, non-filtered coffee, which includes espresso coffee, is the main preparation method for coffee consumed in Spain and Greece $^{(5,15)}$.

Unfortunately, the National Dietary Survey asked individuals about how they sweeten beverages in general and did not obtain information regarding how they sweeten their coffee in particular. In the present study, the most common way to sweeten beverages was with sugar ( $87 \%$ of participants). However, Souza et al. ${ }^{(11)}$, using data from the National Dietary Survey based on the first day of food record, calculated a $10 \%$ amount of added sugar for respondents who reported using sugar and a 5\% amount of added sugar for respondents who reported using both sugar and no-energy artificial sweeteners. These authors found that coffee was the primary source of total sugar consumption among individuals in the lowest income level and the second major source of total sugar in the Brazilian diet ${ }^{(11)}$. A nationally representative estimate of sugar-sweetened beverage consumption in the United States also found that sweetened coffee was one of the top sources of added sugars among adults ${ }^{(25)}$. To the best of our knowledge, there are no studies in Brazil that quantify the methods for sweetening coffee or the amount of sugar added to this particular beverage.

In addition to its well-known stimulant and diuretic properties, recent research has shown the importance of bioactive compounds in coffee ${ }^{(3,4)}$. Based on the concentration of caffeine and chlorogenic acids reported by Machado et al. ${ }^{(14)}$ for one brand of Brazilian coffee ( $84 \mathrm{mg}$ chlorogenic acid/ $100 \mathrm{ml}$ and $146 \mathrm{mg}$ caffeine $/ 100 \mathrm{ml}$ ), we calculated that the average usual daily coffee intake $(163 \mathrm{ml})$ provides $137 \mathrm{mg}$ of chlorogenic acids and $238 \mathrm{mg}$ of caffeine; and the highest daily usual intake $(521 \mathrm{ml})$ provides $761 \mathrm{mg}$ of caffeine and $438 \mathrm{mg}$ of chlorogenic acids. These findings indicate that the amount of caffeine in the average usual daily coffee intake is below the $400 \mathrm{mg} / \mathrm{d}$ recommendation ${ }^{(26)}$

One strength of the present study was its use of a representative and large nationwide sample, which allowed us to characterise the usual daily coffee intake of the Brazilian population. The results are also important for an international audience, seeing as they report representative usual intake of a common beverage drunk by males and females. The consumption of caffeine-containing beverages by women is of particular interest ${ }^{(5)}$. Additionally, dietary intake varies considerably from day to day. Therefore, a key concept in assessing adherence to food intake recommendations is usual intake. The estimation of any usual food intake, including coffee, requires the correct application of adequate methods to assess the long-term average daily intake, which is the value that is necessary to epidemiologists and diethealth relationship studies. One limitation is that the data we used were originally collected to better understand household food availability and individual consumption, but they are not specific for coffee intake. Thus, some questions, such as the amount of sugar used and the reasons for consuming coffee, could not be described.

\section{Conclusions}

Coffee holds a prominent position among the most commonly consumed beverages by Brazilians and represents a major vehicle for antioxidants, licit stimulants and sweeteners in the diet. Older Brazilian men consume higher quantities of coffee than older women, but no difference was identified 
within the age groups between males and females. The age change in coffee intake differs among the Brazilian regions. To our knowledge, this was the first study to describe and characterise usual daily coffee intake in Brazil. The present results make it clear that surveying usual coffee intake is one way of monitoring the characteristics of a population's consumption, and they also describe the methods of coffee preparation and additional ingredients that are used to appreciate coffee. Understanding the habits and consumption of coffee in different cultures is relevant to the market and has potential for nutritional interventions. Usual intake is an important and useful resource for the scientific community, regulatory agencies, industry and public health professionals.

\section{Supplementary material}

To view supplementary material for the present article, please visit http://dx.doi.org/10.1017/S0007114515000835

\section{Acknowledgements}

The authors thank Dr Rosely Sichieri and the staff of the Department of Epidemiology of the Institute of Social Medicine at the State University of Rio de Janeiro for their support in the present study.

A Master's scholarship was granted to A. G. S. and support research was granted to T. H. M. d. C. (no. 302520/2008-2) by CNPq (Conselho Nacional de Desenvolvimento Científico e Tecnológico - National Council for Scientific and Technological Development).

The authors' contributions are as follows: A. G. S. contributed to the study design, organisation of the database and data analyses; T. H. M. d. C. contributed to the study concept and design, data analysis, critical review of the manuscript and study supervision. Both authors participated in drafting the manuscript and read and approved the final manuscript.

The authors have no financial or personal conflicts of interest to declare.

\section{References}

1. Associação Brasileira da Indústria de Café (ABIC) (2010) Indicadores da indústria de café no Brasil (Coffee industry indicators in Brazil). http://www.abic.com.br (accessed July 2013).

2. Souza AM, Pereira RA, Yokoo EM, et al. (2013) Alimentos mais consumidos no Brasil: Inquérito Nacional de Alimentação 2008-2009 (Most consumed foods in Brazil: National Dietary Survey 2008-2009). Rev Saúde Públ 47, Suppl. 1, 190S-199S

3. Dórea JG \& Da Costa THM (2005) Is coffee a functional food? Br J Nutr 93, 773-782.

4. Natella F \& Scaccini C (2012) Role of coffee in modulation of diabetes risk. Nutr Rev 70, 207-217.

5. Lopez-Garcia E, Guallar-Castillon P, Leon-Muñoz L, et al. (2013) Coffee consumption and health-related quality of life. Clin Nutr 33, 143-149.
6. Drewnowski A, Rehm CD \& Constant F (2013) Water and beverage consumption among adults in the United States: cross-sectional study using data from NHANES 2005-2010. BMC Public Health 13, 1068.

7. Garriguet D (2008) Beverage consumption of Canadian adults. Health Rep 19, 23-29.

8. Tooze JA, Midthune D, Dodd KW, et al. (2006) A new statistical method for estimating the distribution of usual intake of episodically consumed foods with application to their distribution. J Am Diet Assoc 106, 1575-1587.

9. Instituto Brasileiro de Geografia e Estatística (IBGE) (2011) Pesquisa de Orçamentos Familiares, 2008-9: Análise do consumo alimentar pessoal no Brasil (Household Budget Survey, 2008-9: Analysis of Individual Food Intake in Brazil). Rio de Janeiro: IBGE. http://www.ibge.gov. br/home/estatistica/populacao/condicaodevida/pof/2008_ 2009_analise_consumo/pofanalise_2008_2009.pdf (accessed June 2013).

10. Da Costa THM \& Gigante DP (2013) Fatos e perspectivas do primeiro Inquérito Nacional de Alimentação (Facts and prospects of the first National Dietary Survey). Rev Saúde Públ 47, Suppl. 1, 166S-170S.

11. Souza AM, Bezerra IN, Peterson KE, et al. (2013) Main food sources of sugar in Brazil: the National Dietary Survey, 2008-2009. FASEB J 27, 847.12.

12. National Cancer Institute (2011) Usual dietary intakes: the NCI method. In Risk Factor Monitoring and Methods. Bethesda, MD: US Department of Health and Human Services, National Institutes of Health. http://riskfactor.cancer.gov/diet/ usualintakes/details.html (accessed June 2013).

13. Barbosa FS, Sichieri R \& Junger WL (2013) Assessing usual dietary intake in complex sample design surveys: the National Dietary Survey. Rev Saúde Públ 47, Suppl. 1, 171s-176s.

14. Machado LMM, Da Costa THM, Da Silva EF, et al. (2011) Association of moderate coffee intake with self-reported diabetes among urban Brazilians. Int J Environ Res Publ Health 8, 3216-3231.

15. Panagiotakos DB, Lionis C, Zeimbekis A, et al. (2007) Longterm, moderate coffee consumption is associated with lower prevalence of diabetes mellitus among elderly non-tea drinkers from the Mediterranean islands (MEDIS Study). Rev Diabet Stud 4, 105-112.

16. Van Dam RM, Dekker JM \& Nijpels G (2004) Coffee consumption and incidence of impaired fasting glucose, impaired glucose tolerance, and type-2 diabetes: The Hoorn Study. Diabetologia 47, 2152-2159.

17. Sartorelli DS, Fagherazzi G, Balkau B, et al. (2010) Differential effects of coffee on the risk of type 2 diabetes according to meal consumption in a French cohort of women: the E3N/EPIC cohort study. Am J Clin Nutr 91, 1002-1012.

18. Agardh EE, Carlsson S, Ahlbom A, et al. (2004) Coffee consumption, type 2 diabetes and impaired glucose tolerance in Swedish men and women. J Intern Med 255, 645-652.

19. Floegel A, Pischon T, Bergmann MM, et al. (2012) Coffee consumption and risk of chronic disease in the European Prospective Investigation into Cancer and Nutrition (EPIC)Germany study. Am J Clin Nutr 95, 901-908.

20. Demura S, Hiroki A, Toshihide M, et al. (2013) Gender differences in coffee consumption and its effects in young people. Food Nutr Sci 4, 748-757.

21. Machado LMM, Araújo MS, Silva EF, et al. (2009) Coffee consumption associated with physical activity, age, sex, and intake of high-energy, protein-rich foods among workers in the city of Belém, Pará, Brazil. Intern J Nutr Welln 7, 1-11. 
22. Mennen LI, Courcy GP, De Guilland J-C, et al. (2002) Homocysteine, cardiovascular disease risk factors, and habitual diet in French Supplementation with Antioxidante Vitamins and Minerals Study. Am J Clin Nutr 76, 1279-1289.

23. Rodenburg EM, Eijgelsheim M, Geleijnse JM, et al. (2012) CYP1A2 and coffee intake and the modifying effect of sex, age, and smoking. Am J Clin Nutr 96, 182-187.

24. Andrade RG, Pereira RA \& Sichieri R (2009) Mudanças no consumo alimentar de mulheres do Município do Rio de
Janeiro, Brasil (Changing in dietary intake by women in the Municipality of Rio de Janeiro, Brazil, from 1995 to 2005). Cad Saúde Pública 25, 2419-2432.

25. Miller PE, McKinnon RA, Krebs-Smith SM, et al. (2013) Sugar-sweetened beverage consumption in the US: novel assessment methodology. Am J Prev Med 45, 416-421.

26. Heckman MA, Weil J \& De Mejia EG (2010) Caffeine (1, 7-trimethylxanthine) in foods: a comprehensive review on consumption, functionality, safety, and regulatory matters. J Food Sci 75, R77-R87. 